\title{
Donald Griffin Strove to give Animals their Due
}

Those of us who are fortunate to study animal behaviour cannot but marvel at the seemingly conscious and intelligent behaviours that animals sometimes display. Birds are known to adapt the behaviour they use to obtain insects from under the barks of trees, to steal cream from milk bottles covered with metal foil. Robert Hinde and others in England showed that such behavi our was 'invented' by a few individuals and then copied by many others. J ane Goodall has described how chimpanzees will select a small branch, remove leaves and twigs and thus fashion it into a suitable tool, carry it to a termite's nest and then use it to retrieve termites by probing with it. Alex $\mathrm{K}$ acelnik at Oxford and others have shown how crows can bend pieces of metal wire and fashion hooks with which they retrieve worms from bottles. Closer home, Milind W atve and his students have shown that bee eaters will not approach their nests if they spot intruders to whom they are visible, but will do so if they spot intruders to whom they are not visible, suggesting that bee eaters have what psychologists call a 'theory of mind'. In our own research, we have found numerous instances of members of social wasp colonies behaving in seemingly intelligent ways. F or example, groups of workers will revolt against the queen and leave together to start their own colony, a given set of workers will cooperate with some queens and not others, workers will sometimes show preferential behaviour towards one but not another dominant individual.

Ethologists, behavioural ecologists and sociobiologists, as we variously call ourselves, have (at least until recently) steadfastly refused to attribute any form of consciousness, awareness or intelligence to animals performing these and many other impressive feats. Instead, it is routine to consider animals as being programmed like robots, to produce expected responses to the stimuli they encounter. It is true that to understand the evolutionary consequences of the behaviour patterns, for example, it is not necessary to attribute consciousness to the animals performing these behaviours. Some of us have begun to feel that in our eagerness to prevent the problem of animal intelligence and consciousness from becoming a stumbling block in the acceptance of our sociobiological theories, we have gone overboard and entirely ignored the possibility that animals may sometime be conscious of their actions.

Without doubt, D onald Griffin (1915-2003) was almost single-handedly responsible 
for this change of heart in at least some of us. Griffin made his name by discovering echolocation in bats and writing a widely accessible book L istening in the dark. In the early 1970's, Griffin decided to devote himself to the cause of animals' consciousness. From then until his death in November 2003, at the age of 88 , Griffin used every possible means available to him to promote the study of animal minds. He wrote and lectured extensively, reinterpreted many old observations, challenged people studying diverse groups of animals to devise ways of obtaining a glimpse into the minds of animals and wrote three books. The burden of Griffin's message was that, viewing animals as being in a state comparable to human sleepwalkers, will never let us find out if animals have conscious experiences. It is of course possible to define consciousness as a subjective experience and claim that the only way we know that other human beings have consciousness is because they communicate their experiences to us through language. With such a definition, animal consciousness is unknowable. Clearly, such a definition is not very useful. The aim is not to show that animals are the same as humans. Instead, the aim is to explore the limits of animal behaviour as it borders on intelligence, awareness and consciousness. Griffin defined consciousness in animals as the 'versatile adaptability of behaviour to changing circumstances and challenges'. Griffin suggested that we should make a three-pronged attack on the problem. First, we should focus on the abilities of animals to behave in versatile ways in response to novel situations. Second, we should explore the neurophysiological correlates of consciousness in humans and search for similar neurophysiological phenomena in animals. Third, we should focus especially on communicative behaviour in animals because he argued that communication provides an especially useful window to the minds of animals. He cautioned that we can only use this window effectively if we stop thinking of animal communication signals as "groans of pain" and start thinking of them as an attempt on the part of animals to assess other animals' moods and thoughts and thereby predict their probable behavioural responses.

Perhaps the most impressive example of animal communication is the dance language of honey bees. A forager bee will return home and perform a dance which contains information about the quality/quantity of food it has discovered as well as about the distance and direction to the food source. Bees closely following the dancer on the nest comb will then be able to locate the food source on their own, without being led to the spot by the dancing bee. Recent research has uncovered an impressive degree of flexibility and variability of the honey bee dance language, making it a prime candidate to explore the possibility of awareness and consciousness in invertebrates. 
By and large Griffin's writings on this subject have met with harsh criticism primarily because his critics continue to define consciousness in a way that excludes the possibility that we can find out if it exists in animals and then claim that Griffin has not produced any definitive evidence, the 'smoking gun', for his belief in animal consciousness. Undaunted, Griffin carried on till the very end and herein lies an important lesson both for us as individuals and for us as a scientific community. If some of us are inspired to persist in studying what we believe is important in the face of widespread scepticism, D onald Griffin's efforts would not have gone in vain. The lesson for the scientific community is more complex and perhaps controversial. The lesson I would draw is that the scientific community should find ways of identifying the best minds and give them the licence to pursue their ideas unfettered by excessive peer pressure, up until the time their ideas begin to fail. This is the only way we will know the limits of any idea. The scientific community has much to gain from competent radicals such as D onald Griffin.

\section{Suggested Reading}

[1] R G adagkar, S urvival S trategies- cooperation and conflictin animal societies, U niversities Press, H yderabad, 1997.

[2] D R G riffin, The question of animal awareness: evolutionary continuity of mental experience, Rockefeller University Press, New Y ork, 1976.

[3] D R G riffin, Animal thinking, H arvard U niversity Press, C ambridge, 1984.

[4] D R G riffin, Animal minds: beyond cognition to consciousness, U niversity of Chicago Press, Chicago, 2001.

[5] B Smitha, J T hakar and M G Watve, D o bee-eaters have a theory of mind?, C urr. S ci., Vol. 76, pp.574-577, 1999.

R aghavendra Gadagkar

Centre for E cological Sciences Indian Institute of Science, B angalore 560 012, India

E mail: ragh@ ces.iisc.ernet.in

and

Evolutionary and O rganismal B iology U nit J awaharlal $\mathrm{N}$ ehru C entre for $\mathrm{A}$ dvanced $\mathrm{S}$ cientific R esearch J akkur P.0., B angalore 560 064, India 